NASA/TM-2004-213072

Update on SLD Engineering Tools Development

Dean R. Miller, Mark G. Potapczuk, and Thomas H. Bond

Glenn Research Center, Cleveland, Ohio 
Since its founding, NASA has been dedicated to the advancement of aeronautics and space science. The NASA Scientific and Technical Information (STI) Program Office plays a key part in helping NASA maintain this important role.

The NASA STI Program Office is operated by Langley Research Center, the Lead Center for NASA's scientific and technical information. The NASA STI Program Office provides access to the NASA STI Database, the largest collection of aeronautical and space science STI in the world. The Program Office is also NASA's institutional mechanism for disseminating the results of its research and development activities. These results are published by NASA in the NASA STI Report Series, which includes the following report types:

- $\quad$ TECHNICAL PUBLICATION. Reports of completed research or a major significant phase of research that present the results of NASA programs and include extensive data or theoretical analysis. Includes compilations of significant scientific and technical data and information deemed to be of continuing reference value. NASA's counterpart of peerreviewed formal professional papers but has less stringent limitations on manuscript length and extent of graphic presentations.

- TECHNICAL MEMORANDUM. Scientific and technical findings that are preliminary or of specialized interest, e.g., quick release reports, working papers, and bibliographies that contain minimal annotation. Does not contain extensive analysis.

- CONTRACTOR REPORT. Scientific and technical findings by NASA-sponsored contractors and grantees.
- CONFERENCE PUBLICATION. Collected papers from scientific and technical conferences, symposia, seminars, or other meetings sponsored or cosponsored by NASA.

- SPECIAL PUBLICATION. Scientific, technical, or historical information from NASA programs, projects, and missions, often concerned with subjects having substantial public interest.

- TECHNICAL TRANSLATION. Englishlanguage translations of foreign scientific and technical material pertinent to NASA's mission.

Specialized services that complement the STI Program Office's diverse offerings include creating custom thesauri, building customized databases, organizing and publishing research results ... even providing videos.

For more information about the NASA STI Program Office, see the following:

- Access the NASA STI Program Home Page at http://www.sti.nasa.gov

- E-mail your question via the Internet to help@sti.nasa.gov

- Fax your question to the NASA Access Help Desk at 301-621-0134

- Telephone the NASA Access Help Desk at 301-621-0390

- Write to:

NASA Access Help Desk

NASA Center for AeroSpace Information 7121 Standard Drive

Hanover, MD 21076 
NASA/TM-2004-213072

\section{Update on SLD Engineering Tools Development}

Dean R. Miller, Mark G. Potapczuk, and Thomas H. Bond

Glenn Research Center, Cleveland, Ohio

Prepared for the

FAA In-Flight Icing/Ground De-Icing International Conference sponsored by the Society of Automotive Engineers

Chicago, Illinois, June 16-20, 2003

National Aeronautics and

Space Administration

Glenn Research Center 


\section{Acknowledgments}

The authors would like to thank Roger Gent, QinetiQ, Didier Guffond and Robert Henry, ONERA, and James Riley and Gene Hill for their significant feedback and support in developing these SLD Engineering Tool Development plans. The authors would also like to thank members of the Ice Protection Harmonization Working Group, the FAA/JAA/TC Technical Team, the Aircraft Manufacturers, and other international research partners who have also provided comments and input to this planning effort.

Available from

NASA Center for Aerospace Information 7121 Standard Drive

Hanover, MD 21076
National Technical Information Service 5285 Port Royal Road Springfield, VA 22100 


\title{
Update On SLD Engineering Tools Development
}

\author{
Dean R. Miller, Mark G. Potapczuk, and Thomas H. Bond \\ National Aeronautics and Space Administration \\ Glenn Research Center \\ Cleveland, Ohio 44135
}

\begin{abstract}
The airworthiness authorities (FAA, JAA, Transport Canada) will be releasing a draft rule in the 2006 timeframe concerning the operation of aircraft in a Supercooled Large Droplet (SLD) environment aloft. The draft rule will require aircraft manufacturers to demonstrate that their aircraft can operate safely in an SLD environment for a period of time to facilitate a safe exit from the condition.
\end{abstract}

It is anticipated that aircraft manufacturers will require a capability to demonstrate compliance with this rule via experimental means (icing tunnels or tankers) and by analytical means (ice prediction codes). Since existing icing research facilities and analytical codes were not developed to account for SLD conditions, current engineering tools are not adequate to support compliance activities in SLD conditions. Therefore, existing capabilities need to be augmented to include SLD conditions.

In response to this need, NASA and its partners conceived a strategy or Roadmap for developing experimental \& analytical SLD simulation tools. Following review and refinement by the airworthiness authorities and other international research partners, this technical strategy has been crystallized into a project plan to guide the SLD Engineering Tool Development effort.

This paper will provide a brief overview of the latest version of the project plan and technical rationale, and provide a status of selected SLD Engineering Tool Development research tasks which are currently underway.

\section{INTRODUCTION}

The roots of the SLD Engineering Tool Development effort can be traced back to recommendations resulting from the National Transportation Safety Board (NTSB) investigation of the ATR-72 crash in 1994.

These recommendations, other aircraft incidents occurring in SLD conditions, and an effort by international regulatory authorities to harmonize icing regulations resulted in the formation of the Ice Protection Harmonization Working Group (IPHWG) through Terms Of Reference (TOR) announced by the Aviation Rulemaking Advisory Committee (ARAC). Of the various tasks to be accomplished by the IPHWG, it was Task 2 which established the basis for a new operational rule affecting aircraft operations in SLD conditions. This draft rule is currently being formulated and is expected to be released in the 2006 timeframe.

IPHWG Task 2 states: " Review National Transportation Safety Board Recommendations A-96-54, A-96-56, and A-96-58, and advances in ice protection state-of-the-art. In light of this review, define an icing environment that includes supercooled large droplets (SLD), and devise requirements to assess the ability of aircraft to safely operate either for the period of time to exit or to operate without restriction in SLD aloft, in SLD at or near the surface, and in mixed phase conditions if such conditions are determined to be more hazardous than the liquid phase icing environment containing supercooled water droplets. Consider the effects of icing requirement changes on 14 CFR part 23 and part 25 and revise the regulations if necessary ..."

It is anticipated that, along with any natural conditions flight test requirements, aircraft manufacturers will require the capability to demonstrate compliance with any new SLD rule via experimental means (icing tunnels or tankers) and analytical means (ice prediction codes). With the increasing costs of flight testing and the improved performance of engineering design tools, aircraft manufacturers are relying more heavily on simulation tools (analytical and experimental) to help minimize certification costs.

The motivation for developing SLD Engineering Tools stems from:

1. The acknowledgement that aircraft manufacturers are expected to rely on icing research facilities and analytical ice prediction computer codes as means to demonstrate compliance with the SLD operational rule 
2. The recognition that current icing research facilities and analytical codes used as a means of compliance for Appendix $\mathrm{C}$ were not developed to include SLD conditions and therefore need to be upgraded to include SLD conditions

As a result of this need, the National Aeronautics and Space Administration (NASA) with the help of the Federal Aviation Administration (FAA), and other international partners such as the Civil Aviation Authority (CAA), QinetiQ, and the Office National d'Etudes et da Recherches Aerospatiale (ONERA) constructed a technical plan to develop SLD engineering tools for design and certification of aircraft in SLD conditions.

This technical plan was embodied in the form of an SLD Technology Roadmap. The roadmap was developed by identifying all of the key technology elements necessary to result in validated SLD engineering tools.

First the major technical areas were identified:

- Atmospheric Environment

- Instrumentation

- Simulation Capability In Icing Research Facilities

- Test Methods

- Analytical Icing Codes

Next, the key sub-elements for research investment within each major technical area were identified and logically connected together. The result of this effort was the document shown in Figure 1. More details about the development of the SLD Technology Roadmap and international partnerships can be found in reference 1.

\section{SLD ENGINEERING TOOLS PROJECT PLAN}

As the SLD Technology Roadmap matured, it became necessary to translate the SLD Technology Roadmap into a project plan having a schedule and Work Breakdown Structure (WBS). This was done to allow all of the partners in the SLD Engineering Tools Development effort to focus their efforts on the specific technical tasks required to ensure timely delivery of accurate and robust SLD engineering tools.

A draft SLD Engineering Tool Development Project Plan was developed based on the Roadmap. Detailed technical tasks (including rationale, schedule, and resource estimates) were developed for each of the technical elements originally identified in the SLD Technology Roadmap. Where possible, research partners were associated with specific tasks.

Initial reviews of the draft SLD Engineering Tool Project Plan by the FAA, indicated that the plan was very comprehensive, but to implement the entire project plan might extend beyond 2006. Some tasks were viewed to be longer term and of lower priority. When viewed from a certification perspective some tasks were deemed to be of higher priority than others: (1) capability to simulate SLD in facilities (tunnels, tankers), and (2) capability to scale SLD conditions.

\section{PROJECT PLAN VERSION 0.5}

Given this feedback, the draft SLD Engineering Tool Development Project Plan was then de-scoped and reprioritized. To do this we assumed the perspective of an airworthiness authority or aircraft manufacturer, and asked ourselves the question: "What tools (i.e.capabilities) are absolutely required to demonstrate compliance with the SLD ops rule?" The result of this revision process was the identification of the following 4 primary technical areas:

- SLD Simulation Capability ... simulate SLD conditions and generate SLD ice shapes with facilities and codes

- Scaling Capability ... scale SLD icing conditions based on facility or test article constraints

- Instrumentation Capability ... accurately measure SLD icing conditions

- Universal Methodology ... translate SLD simulation methodologies developed using NASA IRT into a "generic" form which could potentially be adapted by other icing research facilities

The revised SLD Engineering Tools Project Plan was then released as version 0.5. ${ }^{1}$ This version of the Project Plan was then subjected to another series of reviews by the FAA/JAA/TC technical team, the IPHWG, and also by the aircraft manufacturers located in Wichita, Kansas.

Feedback received from the aircraft manufacturers indicated a desire to emphasize the use of analytical simulation tools (such as ice prediction computer codes) in certification activities, because of the potential for reducing development times, and lowering certification costs. This was somewhat in contrast to comments received from airworthiness authorities who tended to place more emphasis on the development of experimental SLD simulation tools (such as icing tunnels/tankers and experimental methods like scaling). Taken as a whole, this feedback confirmed our fundamental belief about the importance of a balanced SLD Engineering Tool Development Project Plan which provides for the development of both experimental and analytical capabilities.

Comments received from the aircraft manufacturers after reviewing the SLD Engineering Tools Project Plan are summarized below in terms of needed SLD Tool capabilities: 
1. Accurate determination of SLD collection efficiency and icing limits

2. Prediction of SLD ice shapes aft of protected areas to facilitate aerodynamic performance impact assessment

3. Characterization of SLD runback ice (development of an analytical capability was encouraged) to facilitate aerodynamic performance impact assessment

4. Extension of current scaling relationships to nonlifting surfaces

5. Standardized instrumentation to characterize SLD conditions which may not be research grade fidelity, but which are adequate for certification purposes

6. Development of SLD spray capability for tankers

\section{SLD PROJECT PLAN VERSION 1.0}

After evaluating the comments received on version 0.5 , the SLD Engineering Tool Development Project Plan was revised again and released as version 1.0. As of this date, it represents the latest version of the SLD Project Plan. A description of the WBS Tasks for version 1.0 of the Project Plan can be found in the appendix section of this paper. Figure 2 shows a high level organizational chart which identifies some of the sub-elements associated with the 4 major technical areas of the SLD Project Plan WBS.

The objective of WBS element 1.0 is to develop an experimental and analytical SLD simulation capability. For icing wind tunnels (WBS 1.2) \& icing tankers (WBS 1.4) this simulation capability will involve generating a stable, uniform, supercooled large droplet icing cloud, which in turn can be used to generate SLD ice shapes that are to some degree representative of the natural environment. For ice prediction codes (WBS 1.3), this simulation capability will involve the prediction of SLD impingement characteristics (collection efficiency, impingement limits), and generation of representative SLD ice shapes.

Probably one of the most important tasks within WBS element 1.0, if not the entire project plan, is the definition of simulation requirements in WBS 1.1. These requirements are needed to define the essential characteristics to be simulated, as well as the metrics defining the required accuracy for these characteristics. The simulation requirements basically provide the "target" for the simulation development. It is expected that the SLD atmospheric definition derived by the IPHWG will play a critical role in the requirements definition process.

WBS element 2.0 is concerned with developing an SLD scaling capability similar to what has been done for Appendix $\mathrm{C}$ icing conditions. This capability would enable SLD icing conditions to be scaled to support sub- scale model testing, as well as situations where a desired SLD icing test condition might fall outside the facility's capability to generate SLD conditions. Present Appendix C scaling methods will be evaluated, to see if they can be extended to SLD conditions, or if new methods need to be developed.

The ability to accurately measure SLD icing conditions was deemed to be of great importance, because it supports so many of the research tasks in the SLD Engineering Tool Development effort. Therefore WBS 3.0 is concerned with the development of instrumentation which accurately characterizes the attributes associated with SLD icing conditions. LWC, drop size, icing cloud temperature, ice shape measurement, and humidity are among the types of instrumentation considered within this project plan element.

Instrumentation requirements will be defined in WBS 3.1 by means of sensitivity studies (WBS 3.1.1), a survey of instrumentation needs as perceived by users within the icing community (WBS 3.1.2), and identification of required operational practices (WBS 3.1.3). These requirements will be used to assess the adequacy of existing instrumentation, and provide a basis for defining improvements if necessary.

Universal Methods (WBS 4.0) is the last major element in the SLD Engineering Tool Development Project Plan. It is concerned with the identification and documentation of SLD simulation, scaling, and measurement methodologies developed for use in the NASA IRT and NASA Twin Otter, which can then be adapted and translated for use in other icing research facilities. The intent is to leverage the work done by NASA in developing its SLD simulation capability, and allow other icing research facilities to benefit as they strive to develop their own unique SLD simulation capability.

\section{REVIEW OF PROJECT PLAN PROGRESS}

The initial development and review cycle necessary to define the SLD Engineering Tool Development Project Plan has been completed with release of version 1.0. Looking toward the future, we anticipate that periodic reviews will be scheduled to track progress, solicit input from partners, and modify the project plan as necessary. This approach should provide flexibility to account for changing technical or programmatic priorities, and thus facilitate the development of robust SLD engineering tools in a timely manner.

\section{SUMMARY OF SLD ENGINEERING TOOL RESEARCH}

Of the many research tasks identified in the SLD Engineering Tool Development Project Plan, there are a number of tasks which are currently underway. We have chosen to highlight the status of selected tasks to 
illustrate the scope and diversity of the SLD Engineering Tool Development Project Plan. A brief description and status will be provided for each of the research tasks.

\section{WBS 1.2.1 Assess Capability To Produce SLD}

Task Name: IRT SLD Cloud Calibration

Principal Investigator: Robert Ide, Jack Oldenburg

Organization: NASA Glenn

Objective: Extend range of existing Icing Research Tunnel (IRT) SLD cloud calibration

Approach: Calibrate IRT for drop size conditions in between current 5 discrete SLD icing conditions

Status: The SLD droplet size calibration has been completed. The range of MVD's which can be generated in the IRT ranges from 50 microns to 220 microns. Originally there were only five discrete SLD conditions. Now the icing tunnel has been calibrated to run any MVD between 50 and 220 microns. Icing cloud uniformity tests were also run over the range of SLD MVD's to determine the vertical spatial variation. Measurements were made at six-inch intervals from 1 foot below to 1 foot above tunnel centerline. Generally all variations in MVD were within $+/-10 \%$.

\section{WBS 1.2.2 Simulating SLD Ice Shapes}

Task Name: Acquire New SLD Ice Shape Data

Principal Investigator: Thomas Ratvasky

Organization: NASA Glenn

Objective: Acquire additional SLD ice shapes to augment SLD natural ice shape database

Approach: Fly the NASA Twin Otter through SLD icing conditions. Characterize the SLD cloud microphysical properties (drop size, LWC, temp, etc) with onboard suite of instrumentation and capture visual documentation of wing ice accretions which result from the SLD encounter.

Status: Icing research flights were conducted throughout the Great Lakes Region during February \& March 2003. The flight research data are currently being analyzed.

\section{WBS 1.3.1.1 Droplet Dynamics}

Task Name: Droplet Dynamics Effects

Principal Investigators: S.C. Tan

$$
\text { Michael Papadakis }
$$

Organization: Wichita State University

Objective: Identify droplet dynamic issues relevant to SLD icing

Approach: Evaluate the potential effect of various parameters on the ice accretion process in SLD conditions

- Droplet deformation \& breakup prior to impact

- Droplet splash/deposition/bounce

- Near-wall effects

Status: The potential for droplet distortion/breakup in the vicinity of the airfoil leading edge was evaluated by dividing the flow field in the immediate vicinity of the airfoil into several flow regimes, and then considering the effect of aerodynamic and surface tension forces. The resultant effect on droplet splashing and local collection efficiency in each regime was studied. Results were presented in a 2003 AIAA paper. $^{2}$

\section{WBS 1.3.1.2 Droplet Splashing}

Task Name: Droplet Splashing Effects

Principal Investigator: S.C. Tan

Organization: Wichita State University

Objective: Identify droplet splashing parameters

- incoming droplet size

- outgoing droplet sizes

- incoming and outgoing velocities and angles

- relationships to calculation of mass loss.

Approach: Investigated splash dynamics as a function of drop size, airspeed (30-60 mps), impact angle $\left(20^{\circ}-\right.$ $80^{\circ}$ ), $\mathrm{K}$ factor (83-743), and surface roughness.

Status: Splashing observed for all $\mathrm{K}>80$. Results were presented in a 2003 AIAA paper. ${ }^{3}$

\section{WBS 1.3.1.3 Mass Loss}

Task Name: Ice Mass Measurements On Airfoils

Principal Investigator: Mark Potapczuk

Organization: NASA Glenn

Objectives:

- Determine whether large droplet encounters result in lower mass accumulations than expected from a complete capture of all incoming water

- Determine the relationship between this mass loss effect and cloud droplet diameter

- Investigate the parameters governing this behavior

Approach: Directly measured the mass of ice deposited on a well-defined target geometry under a range of Appendix $C$ and SLD conditions. Constant incoming total water accumulation (Ac) was maintained over a range of droplet size (MVD) conditions. The following parameters were also held constant:

- $\quad \mathrm{K}_{0}$ (modified inertia parameter), $\mathrm{V}$ (velocity)

- $\quad \beta_{0}$ (stagnation collection efficiency), and $\eta$ (freezing fraction)

Obtained ice shape tracings and compared ice mass measurements with LEWICE predictions.

Status: For cases where $A c, K_{0}$, and $V$ were maintained constant, as drop size MVD increased, less mass was measured than predicted by LEWICE. For cases where $\beta_{0}$ and $\eta$ were held constant, results were not as straightforward to interpret. More work in this area was recommended. Results were presented in a 2003 AIAA paper. ${ }^{4}$

Task Name: Numerical Analysis Of Splashing Principal Investigator: Adam Rutkowski

Organization: Case Western Reserve University 
Objectives:

- Used CFD tools to calculate trajectories of splashed droplets from initial impact locations

- Determined if splashed droplets re-impinge or are swept downstream of the airfoil

- Performed parametric studies to determine size, velocity, and splash angle of droplets that will reimpinge on a given clean or iced airfoil geometry.

Approach: For a given location on an airfoil, droplet splashing was simulated by launching a particle from the airfoil surface (clean, or iced) into the flow field. Then the minimum escape velocity necessary to do this was determined. The droplet's trajectory was then tracked to determine if it re-impinged.

Status: CFD analysis indicated that re-impingement was unlikely on clean airfoils but could occur as ice shapes develop. Results were presented in a 2003 AIAA paper. ${ }^{5}$

Task Name: Water Runback Mass Measurements Principal Investigator: Roger Gent

Organization: QinetiQ, NASA

Objective:

Obtain a quantitative value of mass loss due to splashing of large droplets for different cloud droplet size, and liquid water content (LWC)

Approach: 3 different test methods were utilized:

1. Quantify the level of under-reading of an LWC sensor, which was subject to mass loss, by comparison with results from an LWC sensor which was not expected to be affected by splash.

2. Collection and weighing of the water film remaining on the surface of a test specimen and comparison with the predicted intercepted mass of water assuming no splash.

3. Measuring the mass of accreted ice on a model and comparing this with the predicted intercepted mass of water assuming no splash.

Status: Mass loss estimates of 5 to $25 \%$ (50 $\mu \mathrm{m}$ to 180 $\mu \mathrm{m})$ were obtained based on the 1st method, but further research is required to confirm the validity of these results. Difficulties implementing the 2 nd test approach, led to inconclusive findings from this portion of the experiment. Test results based on the 3rd method indicated splash mass loss increased with increasing drop size MVD. These results agreed with trends observed by M. Potapczuk of NASA Glenn. Results were presented in a 2003 AIAA paper. ${ }^{6}$

Task Name: Droplet Splashing Visualization Methods Principal Investigator: Dean Miller

Organization: FAA, NASA Glenn, QinetiQ

Objective: Evaluate high speed, close up visualization methods for use in quantifying droplet splash dynamics

Approach: Generated SLD conditions in the ACT icing wind tunnel which had good visual access. Attempted to capture and evaluate high-speed images of large droplet impact and splash at several airspeeds and impact angles.
Status: High speed images were captured, and it was possible to quantify incoming droplet size and velocity for droplet diameters of $100 \mathrm{um}$ and larger. Results indicated that the imaging system and methods tested were more suited for use with single droplet events versus an icing cloud. The results from this test have not yet been published, but there are plans to do so. The evaluation of other high speed close up imaging systems and methods is planned.

\section{WBS 1.3.3 Collection Efficiency}

Task Name: SLD Ice Shape Collection Efficiency

Principal Investigator: Michael Papadakis

Organization: Wichita State University

Objectives:

- Measure collection efficiency values for SLD conditions

- Create a database for ice accretion code validation

Approach: Measure the collection efficiency of various different aerodynamic geometries in Appendix $\mathrm{C}$ and SLD conditions (airfoils, finite wings, s-duct inlet).

Status: Collection efficiency values for SLD conditions have been measured for several airfoil geometries. An initial database is available for code validation. Results suggest that computer simulation methods over predict collection efficiency values. ${ }^{7}$ This may be due to splashing effects in the measurement process. Tests to examine collection efficiency values on iced airfoil geometries are planned for April 2003.

\section{WBS 2.1.1 Perform Scaling Experiments}

Task Name: SLD Scaling Experiments

Principal Investigator: David Anderson Jen-Ching Tsao

Organization: OAI, NASA Glenn

Objective: Evaluate the applicability of Appendix C scaling methods to SLD conditions

Approach: Conducted tests in the NASA Glenn Icing Research Tunnel. Investigated the ability to scale SLD icing conditions (droplet sizes of $175,120,100$, and 70 $\mu \mathrm{m})$ to $50 \mu \mathrm{m}$, which is the maximum MVD within IRT Appendix-C Cloud Calibration.

Status: Results indicated the ability to successfully scale from a drop size MVD of $120 \mu \mathrm{m}$ and below, to 50 $\mu \mathrm{m}$ (using both the constant Weber number and averaged velocity scaling methods). ${ }^{8} \quad$ Later tests conducted at lower airspeeds, confirmed the ability to successfully scale from a drop size MVD of $160 \mu \mathrm{m}$ to Appendix $C$ drop sizes. The results of these additional SLD scaling tests were presented in a 2003 AIAA paper. $^{9}$

Task Name: Water Film Scaling Studies

Principal Investigators: Alejandro Feo

David Anderson

Organization: INTA, OAI

Objective: Investigate water film thickness effects with respect to scaling methods 
Approach: Develop two spray systems: the first will simulate Appendix C drop sizes and LWC's; the second to simulate SLD conditions. Measure the water film thickness for these conditions and correlate the film thickness with appropriate non-dimensional parameters such as the Weber number and Reynolds number.

Status: A correlation relating LWC to a relative film height $(\mathrm{h} / \mathrm{d})$ was developed for Appendix $\mathrm{C}$ drop sizes and high liquid water contents. Scaling methods using a Weber number based on this relative film height produced ice shapes which were in agreement with shapes produced using average velocity scaling methods. ${ }^{10}$ Current activities are focused on confirming the correlation at lower liquid water contents, which are more representative of Appendix $\mathrm{C}$ conditions. Future work in this area is expected to involve extending this methodology to SLD conditions.

\section{WBS 3.2.1 Liquid Water Content Assessment}

Task Name: Instrumentation Assessment

Principal Investigators: Dean Miller

Organization: NASA Glenn

Ed Emery

Objective: Assess liquid water content devices for use in SLD conditions. Attempt to better quantify accuracy and operational characteristics in SLD conditions.

Approach: The NevZorov Total Water Content (TWC) / Liquid Water Content (LWC) probe, and King LWC probe were tested under controlled SLD conditions in the NASA Glenn IRT. Droplet spectra were measured with particle sizing instrumentation for the SLD conditions tested, and then used to correct the measured LWC for collection efficiency effects on the hot-wire sensing element. The results from the 3 probes were intercompared.

Status: Results confirmed previous work by Meteorological Service of Canada, indicating that the NevZorov TWC probe did not exhibit the reduced measurement response to SLD, which is typical of the King probe, and also the NevZorov LWC probe. Work is continuing on better defining the sources of error in these measurements and their contribution to overall device accuracy.

\section{WBS 3.2.2 Reference Measurement Devices}

Task Name: Reference Liquid Water Content Device Principal Investigators: S. C. Tan Michael Papadakis

Organization: Wichita State University

Objective: Develop a reference standard Liquid Water Content device which is not subject to the limitations of current liquid water content instrumentation and which has $100 \%$ collection efficiency for droplet size ranges typical of Appendix C, and SLD conditions.

Approach: The Iso-kinetic principle will be used to facilitate $100 \%$ capture of liquid water within sample volume. The captured water will then be weighed, allowing direct computation of the LWC.
Status: The probe is in development and is projected for completion in early 2004.

\section{SUMMARY \& CONCLUSION}

The SLD Engineering Tool Development Project Plan evolved from the SLD Technology Roadmap thru review and discussion with airworthiness authorities, aircraft manufacturers, and international research partners. As a result of the review process, the Project Plan has been focused toward developing the necessary SLD simulation capabilities by 2006 .

Version 1.0 of the Project Plan provides a comprehensive guide to tasks which need to be accomplished to facilitate the development of SLD Engineering Tools. The SLD Engineering Tool Development Project Plan is intended to help those organizations interested in sponsoring SLD research to develop and prioritize their research investments.

Given the complexity and international scope associated with the development of SLD engineering tools, collaboration among partners will be essential to the success of this effort. It is believed that the SLD Engineering Tool Development Project Plan provides a basis for this needed coordination and collaboration.

\section{ACKNOWLEDGMENTS}

The authors would like to thank Roger Gent from QinetiQ, Didier Guffond and Robert Henry from ONERA, and James Riley and Gene Hill for their significant feedback and support in developing these SLD Engineering Tool Development plans. The authors would also like to thank members of the Ice Protection Harmonization Working Group, the FAA/JAA/TC Technical Team, the Aircraft Manufacturers, and other international research partners who have also provided comments and input to this planning effort.

\section{REFERENCES}

1. Bond, T. H., Miller, D.R., Potapczuk, M. G., Overview Of SLD Engineering Tools Development; AIAA-2003-0386, Jan 2003.

2. Tan, S. C., Papadakis, M., General Effects Of Large Droplet Dynamics On Ice Accretion Modeling; AIAA2003-0392, Jan 2003.

3. Tan, S. C., Papadakis, M., General Effects Of Large Droplet Dynamics On Ice Accretion Modeling; AIAA2003-0391, Jan 2003.

4. Potapczuk,M., Ice Mass Measurements: Implications For The Ice Accretion Process; AIAA-2003-0387, Jan 2003.

5. Rutkowski, A., Numerical Study Of Droplet Splashing And Re-impingement; AIAA-2003-0388, Jan 2003. 
6. Gent, R. W., Ford, J. M., Moser, R. J., Results From Supercooled Large Droplet Mass Loss Tests In The ACT Luton Icing Wind Tunnel; AIAA-2003-0389, Jan 2003.

7. Papadakis, M., Experimental Investigation Of Water Droplet Impingement On Airfoils, Finite Wings, and an S-Duct Inlet, NASA/TM-2002-211700, Oct 2002.

8. Anderson, D., A Preliminary Study Of Ice Accretion Scaling For SLD Conditions, AIAA-2002-0521, Jan 2002.

9. Anderson, D.N., Tsao, Jen-Ching, Additional Results Of Ice Accretion Scaling At SLD Conditions; AIAA2003-0390, Jan 2003.

10. Anderson, D. N., Feo, A., Ice-Accretion Scaling Using Water-Film Thickness Parameters, AIAA2002-0522, Jan 2002.

\section{DEFINITIONS, ACRONYMS, ABBREVIATIONS}

Ac : Accumulation parameter, dimensionless

$\beta_{0}$; Stagnation collection efficiency, dimensionless

$\mathrm{h} / \mathrm{d}$ : Relative film height, dimensionless

$\mathrm{K}$ : Splashing factor, dimensionless

$\mathrm{K}_{0}$ : Modified inertia parameter, dimensionless

$\eta$ : Freezing fraction, dimensionless

V : Velocity, meters/second

ARAC: Aviation Rulemaking Advisory Committee

CAA: Civil Aviation Authority

FAA: Federal Aviation Administration

IPHWG: Ice Protection Harmonization Working Group

IRT: NASA Glenn Icing Research Tunnel

JAA: Joint Airworthiness Authority

LWC: Liquid Water Content

MVD: Median Volumetric Diameter

NASA: National Aeronautics and Space Administration

ONERA: Office National d'Etudes et da Recherches Aerospatiale

QinetiQ: formerly Defense Evaluation and Research Agency
SLD: Supercooled Large Droplet

TC: Transport Canada

TWC: Total Water Content 


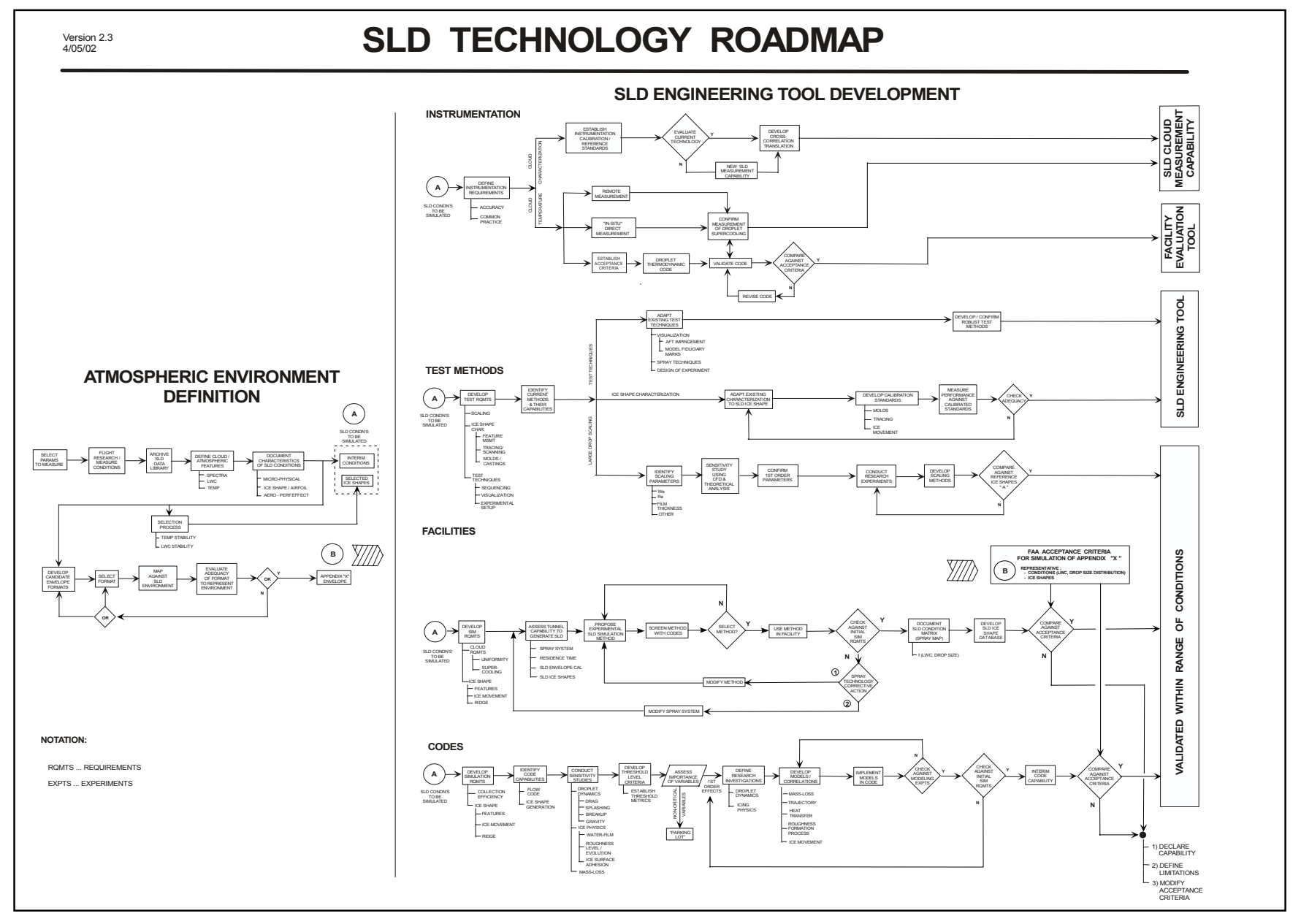

Figure 1 - Supercooled Large Droplet Technology Roadmap 


\section{SLD ENGINEERING TOOL DEVELOPMENT PROJECT PLAN WBS}
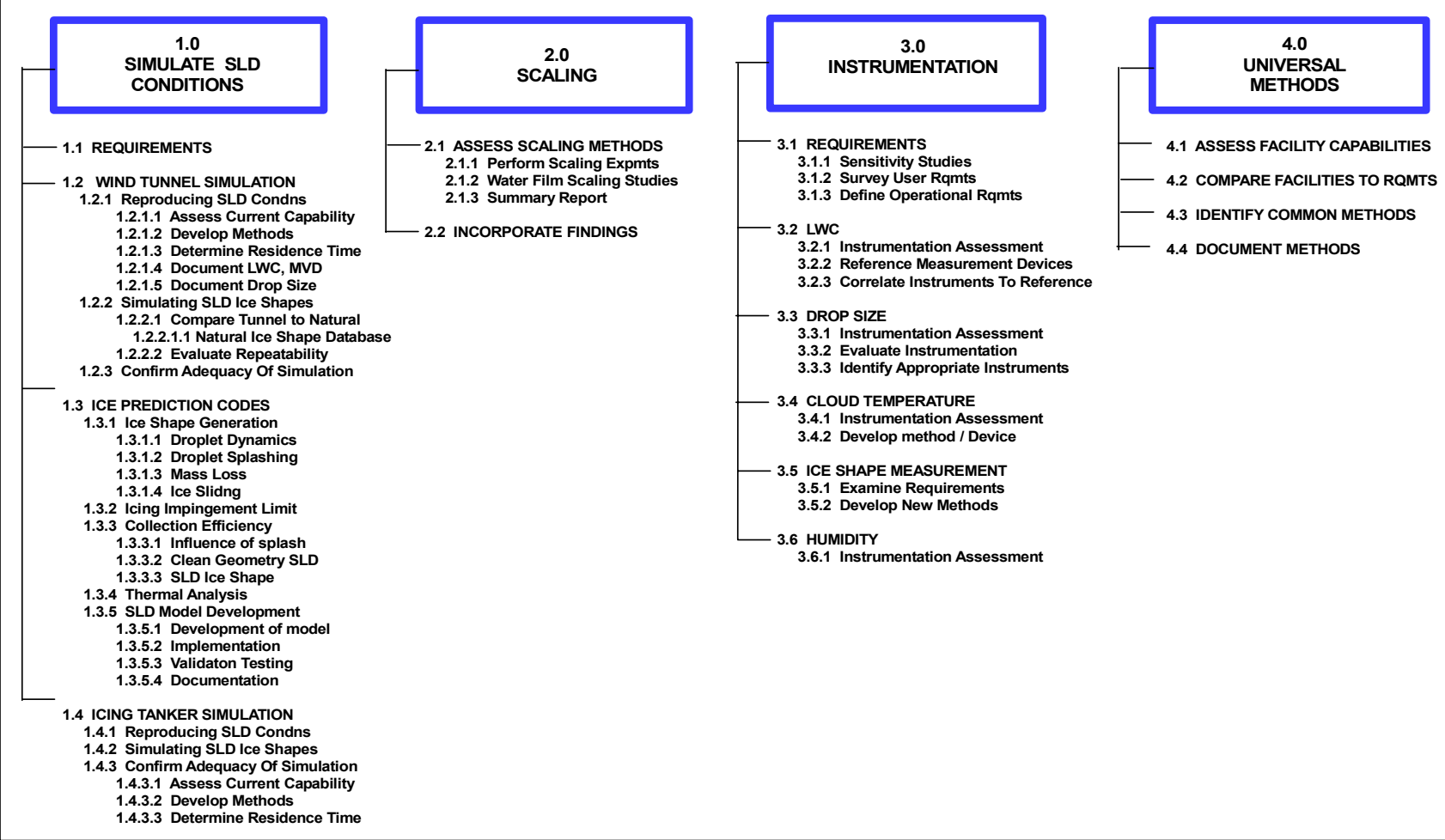

Figure 2 - SLD Engineering Tool Development Project Plan WBS 
APPENDIX:

\title{
SLD Engineering Tools Development Project Plan
}

\section{Work Breakdown Task Descriptions}

\author{
Mark Potapczuk \\ Dean Miller
}

National Aeronautics and Space Administration John H. Glenn Research Center at Lewis Field 


\section{NASA Glenn Research Center Icing Branch}

\section{Revision History}

\begin{tabular}{|c|c|l|l|}
\hline Date & Version & \multicolumn{1}{|c|}{ Description } & \multicolumn{1}{|c|}{ Author } \\
\hline $1 / 3 / 2002$ & 0.1 & Initial version & $\begin{array}{l}\text { Mark Potapczuk; Dean } \\
\text { Miller; Tom Bond }\end{array}$ \\
\hline $2 / 13 / 2002$ & 0.2 & Second draft & $\begin{array}{l}\text { Mark Potapczuk; Dean } \\
\text { Miller; Tom Bond }\end{array}$ \\
\hline $3 / 29 / 2002$ & 0.3 & Third draft & $\begin{array}{l}\text { Mark Potapczuk; Dean } \\
\text { Miller }\end{array}$ \\
\hline $4 / 5 / 2002$ & 0.4 & $\begin{array}{l}\text { Fourth draft - combined elements from } \\
\text { Mark and Dean }\end{array}$ & $\begin{array}{l}\text { Mark Potapczuk; Dean } \\
\text { Miller }\end{array}$ \\
\hline $11 / 15 / 02$ & 0.5 & $\begin{array}{l}\text { Fifth draft - incorporated feedback from } \\
\text { FAA/JAA/TC technical team \& NOQ }\end{array}$ & $\begin{array}{l}\text { Mark Potapczuk, Dean } \\
\text { Miller }\end{array}$ \\
\hline $3 / 18 / 03$ & 0.6 & $\begin{array}{l}\text { Sixth draft -incorporated feedback from } \\
\text { WSU airframers }\end{array}$ & $\begin{array}{l}\text { Mark Potapczuk, Dean } \\
\text { Miller }\end{array}$ \\
\hline $4 / 14 / 03$ & 1.0 & Final draft of WBS & $\begin{array}{l}\text { Mark Potapczuk, Dean } \\
\text { Miller }\end{array}$ \\
\hline
\end{tabular}

This document contains the Work Breakdown Structure (WBS) Task Descriptions of the SLD Engineering Tool Development Project. The WBS is current as of the date associated with this document. Since this project is a research effort, not all of the elements of the WBS are known at the outset of the project. As such, the elements and the period of performance associated with each element are the best estimates as of the date of the document. As the project proceeds, the document will be updated to reflect the current planning and elements will be more fully described as well as modified to reflect changes precipitated by the outcome of earlier elements of the project. 


\section{Introduction:}

The airworthiness authorities (FAA, JAA, Transport Canada) will be releasing a proposed rule in the 2006 timeframe, which concerns the operation of aircraft in an SLD environment aloft. The proposed rule will require aircraft manufacturers to demonstrate that their aircraft can operate safely in an SLD environment for a period of time to facilitate a safe exit from the condition.

It is anticipated that aircraft manufacturers will require the capability to demonstrate compliance with this rule via experimental means (such as icing tunnels, or tankers), and by analytical means (ice prediction codes). Since current icing research facilities and analytical codes were not developed to account for SLD conditions, the capability of these engineering tools need to be upgraded to include SLD conditions.

Given this need, NASA developed an SLD Technology Roadmap to guide the development of an SLD simulation capability in icing research facilities, and analytical codes. The roadmap identified the key technical areas needing development, and provided a logic flow for the required research activities.

An SLD Engineering Tools Development Project Plan (SLD Project Plan) was then developed, based on the SLD Technology Roadmap. This plan was an attempt to translate the SLD Technology Roadmap into a "project" format, by identifying discrete tasks which needed to be accomplished, and then organizing them into a Work Breakdown Structure (WBS).

The SLD Project Plan has been subjected to several stages of review by airworthiness authorities, and international research partners. The result of this review process is the document contained herein. The intent of this document is to list the discrete tasks in a WBS format, provide a brief description or rationale for doing the task, and where possible, associate an organization with the task. Organizations have been associated with tasks if they: 1) indicated an interest in doing a task, or 2) were already actively working in an area.

The association of an organization with a particular task does not constitute a commitment to accomplish the task, only the desire to work on the task. It is expected that once funding and resource allocation issues within each organization have been resolved, organizational commitments can be reflected in this document.

\section{Approach:}

The approach used to develop this document was based on FAA review comments, which recognized that it would not be possible to complete all the items in the SLD Technology Roadmap by the 2006 timeframe. Therefore, they stressed the need to focus on a smaller subset of highest priority technology items such as: 1) facility capabilities to generate SLD, and 2) scaling for SLD conditions.

Considering this feedback, a reduced scope SLD Engineering Tools Development Project Plan was developed. This was accomplished by assuming the viewpoint of an aircraft manufacturer required to comply with the new SLD airworthiness rule, and then asking ourselves the question: "What are the most important SLD Tool capabilities that need to developed to support compliance activities?" Our response to this question formed the basis for this revised SLD Engineering Tools Development Project Plan.

Four key areas were identified for development in the revised project plan:

1) Simulation of SLD conditions in icing research facilities,

2) Scaling of SLD conditions,

3) Instrumentation to measure SLD conditions

4) Universal SLD simulation methodologies 
Further reviews by an FAA/JAA/TC technical team, the Ice Protection Harmonization Working Group, and at an informal meeting with a representative group of aircraft manufacturers lead to further refinements. The notable addition by the manufacturers was support for development of computational tools. They look upon such tools as playing a key role in addressing the issues of certification for SLD conditions and at the same time aiding in keeping costs contained during the certification process. As such, the plan retains elements required for development of such tools.

\section{Scope:}

This document contains a Work Breakdown Structure for the revised SLD Engineering Tools Development Project Plan. The intended use for the document is to provide guidance in the identification of research tasks needed for the development of SLD Engineering Tools.

While this document is focused on developing SLD Engineering Tools applicable to ground based and airborne research facilities, WBS tasks have been more completely defined for Icing Wind Tunnels than for Icing Tanker Aircraft. There are two reasons for this; 1) The authors knowledge \& experience base in icing does not include the use of tanker aircraft to perform icing simulations, and 2) It is expected that organizations operating icing tankers will want to develop the detailed technical tasks. 


\section{Generate/Simulate SLD Icing Conditions}

\subsection{Develop requirements for SLD simulation}

Requirements (or metrics) need to be defined to provide a "target" for SLD simulation in quantified terms. These requirements serve a dual-purpose by providing guidance: 1) about what essential features or characteristics need to be simulated, and 2) about how accurately these characteristics need to be simulated. It is anticipated that these requirements would be developed by means of sensitivity studies, either experimental or computational. Furthermore, these requirements need to be derived taking into account recommendations from the IPHWG.

Objective: Identify the metrics that have to be met to assure adequate simulation of the SLD environment from an engineering perspective. These could include LWC range, drop size range and distribution, ice shape similarity, droplet supercooling, and variation of cloud conditions as a function of time. Included in this study is an assessment of how accurately these elements must be simulated to manifest some difference in desired outcome.

\subsection{SLD simulation with Icing Wind Tunnel}

Two distinct capabilities are needed to replicate SLD conditions in an icing wind tunnel: 1) the capability to generate or reproduce a representative SLD cloud condition (1.2.1), and 2 ) the capability to generate a representative SLD ice shape using those cloud conditions (1.2.2).

\subsubsection{Reproducing SLD Conditions}

This task is focused on developing the capability to generate an SLD icing cloud which is representative of the SLD environment as recommended by the IPHWG Appendix SLD (in document TBD).

\subsubsection{Assess current capability to produce SLD}

Objective: Document what the icing research facility is currently capable of with respect to SLD simulation. Determine whether the current spray system technology is adequate to produce the features of an SLD cloud with respect to the requirements as outlined in Task 1.1. Metrics are icing tunnel cloud size, uniformity, and repeatability. Additional metrics are LWC, and droplet size distribution.

Organization: NASA

\subsubsection{Develop methods to generate SLD cloud}

It may not be possible to exactly match the icing cloud distributions specified by the IPHWG Appendix SLD, with current spray bar technology. Therefore, this task is focused on developing operational methods to utilize existing spraybar technology, and still effectively simulate those IPHWG SLD cloud conditions.

1.2.1.2.1. Investigate and document constant or time varying icing conditions in natural SLD encounters

Objective: Identify the characteristics of a natural cloud that do or don't vary as a function of time during an in-flight icing encounter. These characteristics will be used to guide the development of a simulated encounter in an icing wind tunnel.

Organization: NASA

\subsection{Develop cloud sequencing method}


Objective: Alter icing conditions during a run to simulate the SLD environment. This could allow for temporal variations in the natural cloud as well as for the differences in droplet distribution between natural and icing wind tunnel clouds.

Organization: NASA

\subsubsection{Determine residence time for supercooling}

Residence time has been defined as the time for heated water droplets emanating from the facility spraybars, to reach static tunnel temperature (which if below $0^{\circ} \mathrm{C}$, will be supercooled). Residence time is a function of the distance between the facility spraybars and test article, and varies with tunnel airspeed and water droplet size. To adequately simulate SLD conditions will require that the water droplets in the icing spray cloud be supercooled when they reach the test section or test article. Since it will not be possible to measure the spray cloud temperature in most icing research facilities, an analytical means is needed to determine the range of facility spray conditions which will be supercooled. This task is focused on developing an analytical means to predict the "residence time" required for supercooling, given facility geometry, and tunnel flow conditions

\subsection{Evaluate supercooling with droplet thermodynamic codes}

Objective: Use droplet thermodynamic codes to determine whether the large droplets are supercooled as they reach the test section of the icing wind tunnel. Develop a chart or series or charts that relate supercooling to drop size, tunnel velocity, and distance from spray bars to test section.

Organizations: QinetiQ, ONERA

\subsection{Validation of droplet thermodynamic codes}

Objective: Conduct tests in an icing wind tunnel to measure temperature of cloud droplets using measurement methods developed in 3.4.2. Use the results from this task to validate the analytical estimates of supercooling developed in 1.2.1.3.1.

\section{Organization: NASA}

\subsubsection{Document Range of LWC and MVD vs. Appendix SLD}

Objective: Map out the range of conditions that can be obtained in the icing wind tunnel and compare those to the range identified for Appendix SLD as recommended by the IPHWG (in document TBD). The intent is to identify areas of overlap, and extent of SLD simulation capability.

Note: Project plan for this task needs to be worked out with icing wind tunnel cloud specialists. Tunnel entries may need to be identified.

Organization: NASA

\subsubsection{Document drop size distribution vs. Appendix SLD}

Objective: To compare the icing wind tunnel SLD droplet size distributions against distributions recommended by IPHWG in Appendix SLD (document TBD). Then document the results of this comparison, which should highlight similarities and differences between the respective drop size spectra.

Note: Project plan for this task needs to be worked out with icing wind tunnel cloud specialists. Tunnel entries may need to be identified.

Organization: NASA 


\subsubsection{Simulating SLD Shapes}

This task is focused on developing the capability to generate SLD ice shapes which are representative of the SLD environment as specified by the IPHWG Appendix SLD in (document TBD).

\subsubsection{Compare Icing Wind Tunnel shapes to natural shapes}

To ensure that SLD ice shapes generated in icing facilities have characteristics that are representative of the SLD environment aloft, natural ice shape databases will be compared with SLD ice shapes generated in icing facilities. This task is focused on compiling the necessary tunnel, and flight ice shape databases for similar SLD icing conditions, and then comparing the two sets of ice shapes.

\subsection{Compile database of natural ice shapes}

Current SLD ice shape data is not sufficient to assess the level of agreement between natural and simulated SLD ice shapes. The following tasks have been identified to augment the current in-flight ice shape database.

\subsection{Assess existing database}

Objective: Examine the database of documented SLD flight ice shapes and identify the conditions, body geometry, and ice shape geometry for these cases. Further examine the database to determine those cases for which the data is sufficient to allow use as a validation for an icing wind tunnel or code.

\section{Organization: NASA}

\subsection{Acquire new ice shape data}

Objective: Obtain ice shape data as well as icing conditions for additional flights. It would be desirable to have constant LWC and drop size conditions during the encounters. Further it would be desirable to augment the current database with respect to icing conditions.

\section{Organization: NASA}

\subsection{Compile database of tunnel ice shapes}

Objective: Create and maintain a database of SLD ice shapes for various body geometries and SLD icing conditions. Be sure to obtain conditions that recreate results of SLD icing flights.

\section{Organization: NASA}

\subsection{Compare natural and tunnel ice shape databases}

Objective: Identify those cases where flight and icing wind tunnel conditions can be compared. Assess adequacy of icing wind tunnel to simulate in-flight SLD ice shapes with respect to requirements. Identify conservative approach for simulation. Use comparison methods developed in 3.5.

\section{Organization: NASA}

\subsubsection{Evaluate repeatabilty of facility for generation of SLD shape}

Objective: Conduct tests in icing wind tunnel to quantify repeatability of ice shapes. Correlate with repeatability of spray conditions. Determine if acceptable with respect to requirements. Determine how errors in control of spray bar 
pressures translate into differences in LWC and drop size. Ideally repeatability of cloud conditions should be less than that which produces a significant change in ice shape.

Organization: NASA

\subsubsection{Confirm adequacy of Icing Wind Tunnel to simulate SLD environment}

Objective: Compare simulation capabilities developed in 1.2.1 \& 1.2.2 to requirements developed in 1.1. Document ability of the icing wind tunnel to simulate the SLD icing cloud and to produce ice shapes representative of those from flight conditions.

\subsection{SLD simulation with Ice Prediction Codes}

These tasks are focused on modifying ice accretion codes in order to account for icing physics elements which play a role in SLD ice growth that are not currently included in most ice growth models. Most of the tasks are centered on examination of the physical processes considered important for SLD icing and creating the data necessary to allow the development, modification and validation of SLD icing physics models.

This SLD model development activity will address the issues of simulating SLD ice shapes, collection efficiency characteristics, icing impingement limits, and thermal analysis.

\subsubsection{Shapes}

\subsubsection{Droplet Dynamics}

The larger diameter water droplets of SLD conditions may be more susceptible to deformation and/or break-up due the relatively lower capability of surface tension to maintain the spherical shape and size of the droplet when subjected to the forces present in the flow field surrounding the droplet. Deformation and break-up could impact an SLD ice shape by altering where a droplet impacts or whether it actually does impact on the surface of interest.

\subsection{Analysis of droplet dynamics}

Objective: Identify those processes that could influence the behavior of super-cooled large droplets as they travel towards the target of interest. This could include the differences experienced by droplets in-flight as compared to those found in an icing wind tunnel

Organization: lowa State Univ.

\subsection{Droplet dynamics experiments}

Objective: Determine the range of conditions that may influence the behavior of super-cooled large droplets as they travel towards the target of interest.

Organization: TBD

\subsection{Develop droplet dynamics model}

Objective: Develop a model for inclusion into ice accretion simulation methods of the dynamics identified in tasks 1.3.1.1.1 and 1.3.1.1.2 that may influence the development of ice during the accretion process.

Organization: TBD

\subsubsection{Droplet Splashing}


Identify droplet splashing parameters (incoming droplet size, outgoing droplet sizes, incoming and outgoing velocities and angles, etc.) and relationships to calculation of mass loss. How much incoming mass splashes and how much of the splashed mass re-impinges or escapes from the surface. This information will then be used to develop droplet splash/mass-loss models for incorporation into CFD ice prediction codes. The desired outcome is accurate prediction of SLD ice shapes.

\subsection{NASA Droplet splashing experiment}

Objective: Determine how much incoming mass splashes and how much of the splashed mass reimpinges or escapes from the surface.

Organizations: NASA, Wichita State University

\subsection{Cranfield droplet splashing contract}

This is a CAA sponsored effort to design and build a vertical flow wind tunnel and perform droplet splashing tests.

Objective: Determine the amount of water splashed from the surface during an SLD droplet impact.

\section{Organization: Cranfield University}

\subsection{Analytical Modeling of Splash/Impact Dynamics}

This is the QinetiQ sponsored activity to model the dynamics of the splash/impact process analytically.

Objective: Develop a CFD model which captures the dynamics of droplet impact /splash, and which can be used to estimate mass loss due to splashing.

Organization: University College of London, QinetiQ

\subsection{ONERA droplet splashing experiment}

This experiment will be conducted at CEPr-PAG icing wind tunnel using DMAE/ONERA Toulouse visualization equipment.

Objective: Study effect of water film properties \& surface characteristics on droplet impact/splash dynamics.

Organization: ONERA, CEPr

\subsection{Develop droplet splashing model}

Objective: Take results of droplet splashing experiments and develop computational algorithms that can be added to existing codes to account for droplet splashing (amount and location of mass loss).

Organizations: NASA, ONERA, QinetiQ

\subsubsection{Mass Loss}

\subsection{Ice mass measurements on airfoils}

Objective: Develop a database for validation of mass loss algorithms used in codes. Used to help determine whether splashing plays a significant role in the SLD ice accretion process. This task is analysis and reporting of already completed tests.

\section{Organizations: NASA, QinetiQ}




\subsection{Water runback mass measurements}

Objective: Develop a first order estimate of mass loss due to splashing by measuring the amount of water mass that remains on the surface

Organization: QinetiQ

\subsubsection{Ice Sliding}

Questions about ice sliding first arose in 1996, during a series of exploratory SLD icing tests conducted in the NASA IRT. There were occasions where surface ice accretions were observed to slide back, and refreeze at a new chordwise location, farther aft on the airfoil. This task is intended to determine whether ice sliding is a legitimate phenomena associated with SLD icing, and whether it needs to be modeled with ice prediction codes.

\subsection{Review previous test efforts}

Objective: Examine the videotapes from previous tests and determine which ones had ice sliding occur.

Organizations: NASA, QinetiQ

\subsection{Assess need for further work}

Objective: Determine if there is enough evidence to warrant further investigation.

Organizations: NASA, QinetiQ

\subsubsection{Icing Impingement Limit}

Definition of this task will be deferred until the requirements for icing impingement limit simulation is determined in Task 1.1 The tasks identified under this element of the WBS should provide capabilities to allow evaluation of distribution effects on ice shapes. These were identified by the manufacturers as important for evaluation of impact on ice protection system design and in determination of aerodynamic impact. Particularly they are interested in reducing the over-conservatism in simulation of SLD ice shapes.

\subsubsection{Collection Efficiency}

\subsubsection{Influence of droplet splashing on collection efficiency measurements}

Objective: Quantify the influence of droplet splashing on current collection efficiency measurement methods.

Organization: WSU, FAA, NASA

\subsubsection{Clean geometry SLD collection efficiency study}

Objective: Measure collection efficiency on several representative aircraft component geometries under SLD conditions.

Organization: WSU, FAA, NASA

\subsubsection{SLD Ice Shape Collection Efficiency Study}

Objective: Measure collection efficiency for several sequences of ice shapes on a single airfoil under SLD conditions. The intent is to evaluate how collection efficiency changes as ice shapes develop and to provide validation data for simulation codes.

Organizations: $\quad$ WSU, FAA, NASA 


\subsubsection{Thermal Analysis}

The intent of this work area is to identify and evaluate any features associated with thermal ice protection simulation in SLD conditions that differ from Appendix C conditions.

\subsubsection{SLD Runback Ice}

Objective: Document characteristics of SLD runback ice shapes obtained from operation of a thermal ice protection system in SLD icing conditions. Evaluate the potential effects of runback ice (e.g. - with respect to aircraft performance, control surface operation, etc).

Organizations: NASA, Cessna

\subsubsection{SLD Model Development}

The creation of updated capabilities for SLD modeling in current ice accretion software. The development effort shall conform to industry standards set for design, implementation, version control and documentation used for public release of validated software.

\subsubsection{Development of proposed SLD model}

Objective: Design of icing models for SLD ice accretion incorporating results of experimental activities outlined in sections 1.3.1 through 1.3.4

Organization: NASA, ONERA, QinetiQ

\subsubsection{Implementation}

Objective: Creation and/or modification of software needed to add models of SLD behavior to existing ice accretion prediction software.

Organization: NASA, ONERA, QinetiQ

\subsubsection{Validation Testing}

Objective: Comparison of computational results to existing database of SLD ice shapes. Evaluation of ice shape comparisons using quantitative measures delineated in NASA CR 208690, "Validation Report for LEWICE 2.0".

Organization: NASA, ONERA, QinetiQ

\subsubsection{Documentation}

Objective: Preparation of appropriate technical documents to describe new software capabilities and to document the validation process.

Organization: NASA, ONERA, QinetiQ

\subsection{SLD In-Flight Simulation with Tankers}

Except for any modifications to allow for the unique capabilities of tanker systems, these tasks should be similar in nature to those required to simulate SLD in icing wind tunnels. It is expected that the organizations proposing to simulate the SLD environment with icing tankers, would provide more detail for work in this area. 


\subsubsection{Reproducing SLD Conditions}

Objective: Develop the capability to generate an SLD icing cloud which is representative of the SLD environment as recommended by the IPHWG Appendix SLD (in document TBD).

Organizations: Raytheon, Cessna

\subsubsection{Assess current capability to produce SLD}

Objective: Document what the icing tanker facility is currently capable of with respect to SLD simulation. Determine whether the current spray system technology is adequate to produce the features of an SLD cloud with respect to the requirements as outlined in Task 1.1. Metrics are icing tunnel cloud size, uniformity, and repeatability. Additional metrics are LWC, and droplet size distribution.

Organizations: Raytheon, Cessna

\subsubsection{Develop capability to generate SLD cloud}

Objective: Develop capability to generate SLD conditions with tanker aircraft spray system. This task remains to be defined in more detail.

Organizations: Raytheon, Cessna

\subsubsection{Determine residence time for supercooling}

Residence time has been defined as the time for heated water droplets emanating from the tanker spraybars, to reach static or ambient temperature (which if below $0^{\circ} \mathrm{C}$, will be supercooled). This task is focused on developing the capability to analytically predict "residence time" for tanker aircraft spray clouds.

\subsection{Develop analytical capability to predict supercooling}

Objective: Adapt existing droplet thermodynamics codes or methods (validated for use in icing wind tunnels in 1.2.1.3.2) for use with tanker aircraft spray systems.

Organizations: Raytheon, Cessna

\subsection{Evaluate supercooling with droplet thermodynamic codes}

Objective: Use droplet thermodynamic codes to determine whether the large droplets from the tanker spray cloud are supercooled as they reach the test aircraft. Develop a chart or series or charts that relate supercooling to drop size, aircraft velocity, and distance from spray bars to aircraft under test.

Organizations: Raytheon, Cessna

\subsubsection{Simulating SLD Shapes}

Objective: Develop the capability to generate SLD ice shapes which are representative of the SLD environment as specified by the IPHWG Appendix SLD in (document TBD).

Organizations: Raytheon, Cessna

\subsubsection{Confirm adequacy of tanker to simulate SLD environment}

Objective: Compare simulation capabilities developed in $1.4 .1 \& 1.4 .2$ to requirements developed in 1.1 .

Organizations: Raytheon, Cessna 


\section{Scaling}

\subsection{Assess current scaling methods for use with SLD}

\subsubsection{Scaling requirements}

Objective: Determine what level of accuracy is required for scaling methods to be considered successful. How well do current scaling capabilities aid in providing models that can be used to evaluate characteristics such as impingement/icing limits and aerodynamic parameters.

Organizations: $\quad T B D$

\subsubsection{Perform SLD scaling experiments}

Objective: Use current scaling laws for SLD conditions to determine if the methods currently employed for App. C conditions can be used for SLD.

Organizations: NASA

\subsubsection{Water film scaling studies}

Objective: Determine the scaling methods needed to insure that surface water films can scale over the range of drop sizes that include App. C and SLD.

Organizations: INTA, NASA

\subsubsection{Summary report}

Objective: Write and publish a report on scaling methods for SLD. Identify what methods may be unique for SLD conditions, if any. Provide guidance for engineers performing icing tests under scaled conditions.

Organization: NASA

\subsection{Incorporate new findings into scaling methods}

Objective: Update scaling methods as more information is obtained from continued scaling tests.

Organization: NASA

\section{Instrumentation}

The tasks undertaken in the previous two sections as well as the general process of testing under SLD conditions requires the use of accurate measurement devices for quantities such as water droplet size, liquid water content, temperature, and velocity. Instruments to perform these measurements are currently available for Appendix $C$ icing conditions. It is the intent of this element of the project plan to identify the requirements for such instruments with respect to SLD conditions and to assess the abilities of current instruments to satisfy those requirements.

\subsection{Requirements}

\subsubsection{Sensitivity studies of ice shapes to measurement parameters}

Objective: Perform computational studies using LEWICE to determine the sensitivity of ice shapes to changes in cloud parameters such as LWC, drop size, velocity, temperature, etc. 
This work is related to the activities identified in Task 1.1 and thus there should be some connection between these two tasks.

Organization: NASA

\subsubsection{Survey users on instrumentation requirements}

This task is undertaken in order to obtain a sense of what the icing community thinks is required for accurate determination of quantities of interest for icing simulation.

\subsubsection{Identify user requirements}

Objective: Survey users to determine what they need from icing measurements in terms of accuracy and repeatability.

Organization: NASA, FAA

\subsubsection{Evaluate user requirements}

Objective: Identify if instrumentation used for certification purposes have differing requirements from those used for research. If so, quantify the differences.

Organizations NASA, FAA

\subsubsection{Document user requirements}

Objective: Summarize and document results of user survey.

Organizations NASA, FAA

\subsubsection{Define operational requirements of instruments}

Objective: Identify what additional requirements must be satisfied for appropriate operation of the icing instruments of interest.

Each instrument has additional requirements with respect to how it is set up and operated in order to assure maximum performance. These requirements should be identified and agreed to by the community at large in order to assure uniform reliability by those using such instruments. These requirements should be published in order to promote "best practices" by the community.

Organization: NASA

\subsection{LWC}

\subsubsection{Instrumentation assessment}

Objective: Perform a study to determine what are the current capabilities of LWC measurement instruments. Compare capabilities to requirements identified in Task 3.1

Organization: NASA

\subsubsection{Reference Measurement Devices}

Current icing cloud LWC measurement methods have limitations and varying undefined uncertainties which are affected by air flow velocity, air flow turbulence, absolute water content level, water drop size, and drop size distribution. These performance issues lead to discrepancies when similar devices are tested in different icing facilities. A reference LWC measurement device is needed to eliminate the ambiguity due to these performance issues. This task is focused on developing a 
device, which provides a well-defined measurement of LWC in order to calibrate other existing LWC devices.

\subsubsection{LWC measurement based on slotted airfoil}

Objective: Develop LWC measurement device based on direct collection of water droplets and measurement of the collected mass.

Organization: NASA

\subsubsection{LWC measurement based on iso-kinetic probe (method1)}

Objective: Develop an LWC measurement device based on direct collection of water droplets and measurement of their mass. Principle for collection and measurement is different than that used in Task 3.2.2.1

Organizations: WSU, FAA

\subsubsection{LWC measurement based on iso-kinetic probe (method 2)}

Objective: Develop an LWC measurement device based on iso-kinetic sampling, evaporation of cloud water, and measurement of resulting humidity. Principle for collection and measurement is different than that used in Task 3.2.2.1, and has some features different from Task 3.2.2.2.

Organization: Cranfield University

\subsubsection{Correlate other instruments to reference}

Objective: Once a reference LWC measurement device is developed, compare results to other LWC devices and create correlations to adjust readings of other devices.

Organization: NASA

\subsection{Drop Size}

\subsubsection{Instrumentation assessment}

Objective: Conduct a study to determine what measurement devices are currently available for measurement of drop size and drop size distribution. Determine whether devices are suitable for use with SLD conditions.

Organization: NASA

\subsubsection{Evaluate performance of candidate instruments through comparative testing}

Objective: Conduct a series of tests with the candidate systems identified in Task 3.3.1 to examine their capabilities over the range of conditions specified in Task 1.1

Organization: TBD

\subsubsection{Identify appropriate usage of candidate instruments based on Task} 3.3.2

Objective: Based on the results of testing in Task 3.3.2, recommend appropriate usage of the candidate instruments.

Organization: TBD 


\subsection{Cloud Temperature}

\subsubsection{Instrumentation assessment}

Objective: Examine what devices are currently available for measurement of cloud water droplet temperature.

Organization: NASA

\subsubsection{Develop selected method / device - (TBD depending on selected device)}

Objective: If it is determined from Task 3.4.1 that there is a need for a new device or measurement method, then a plan for development will have to be created.

Organization: TBD

\subsection{Ice Shape}

\subsubsection{Examine requirements for SLD ice shape measurement}

Objective: Determine whether there are different measurements required to characterize SLD ice shapes. Identify those measurements and establish comparison criteria.

Organization: NASA

\subsubsection{Develop new measurement method}

Objective: Based on the findings of task 3.5.1, develop measurement technique for unique SLD ice shape features. This task will only be undertaken if deemed necessary.

Organization: TBD

\subsection{Humidity}

\subsubsection{Instrumentation assessment}

\subsubsection{Define capabilities of current humidity measurements}

Objective: Identify devices used to make humidity measurements currently and whether their current installation is appropriate for accurate assessment of humidity as defined in Task 3.1

Organization: TBD

\subsubsection{Compare current capabilities to requirements identified in Task 3.1}

Objective: Report on what can and can't be determined from current humidity measurements. Make recommendations for improvements, if necessary.

Organization: TBD

\section{Develop a universal methodology for SLD icing simulation}

Icing research facilities will have different capabilities and limitations relative to simulating the SLD environment. Therefore, methods developed under tasks 1 thru 3 of this document should be generalized to provide guidance to other icing research facilities. The intent is provide a "template" for development of SLD simulation methods, which can be adapted to the unique requirements of each facility. 


\subsection{Assess capabilities of all icing facilities}

Objective: Report on known icing facilities based on information that can be provided by owners. This report should be based on characteristics of the facilities needed for generation of SLD conditions.

Organization: NASA, TBD

\subsection{Compare facilities to modeling requirements}

Objective: Report on the potential for each facility to be able to produce SLD conditions based on the findings of Task 4.1 and the requirements identified in Task 1.1

Organization: NASA, TBD

\subsection{Identify methods that can be commonly used}

Objective: Based on the SLD simulation methods developed in Task 1.2, determine practices that are not unique to the IRT and describe in terms that could be put into practice by any facility.

Organization: NASA, TBD

\subsection{Document practices required for simulation}

Objective: Report on the measurements and methods used to allow simulation of SLD environment in the IRT.

Organization: NASA, TBD 



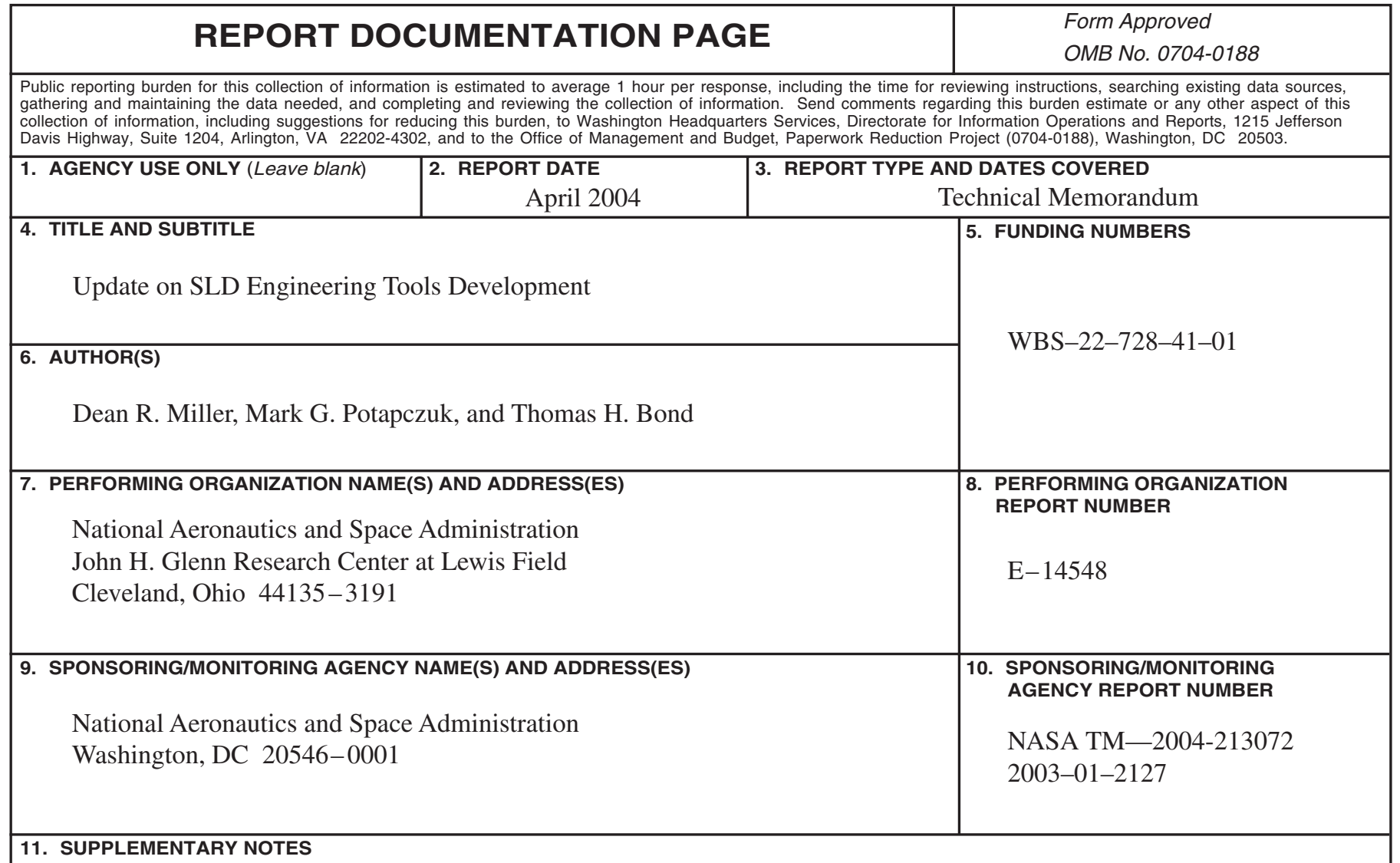

Prepared for the FAA In-Flight Icing/Ground De-Icing International Conference sponsored by the Society of Automotive Engineers, Chicago, Illinois, June 16-20, 2003. Responsible person, Dean R. Miller, organization code 5840, 216-433-5349.

12a. DISTRIBUTION/AVAILABILITY STATEMENT 12b. DISTRIBUTION CODE

Unclassified - Unlimited

Subject Category: 03

Distribution: Nonstandard

Available electronically at http://gltrs.grc.nasa.gov

This publication is available from the NASA Center for AeroSpace Information, 301-621-0390.

\section{ABSTRACT (Maximum 200 words)}

The airworthiness authorities (FAA, JAA, Transport Canada) will be releasing a draft rule in the 2006 timeframe concerning the operation of aircraft in a Supercooled Large Droplet (SLD) environment aloft. The draft rule will require aircraft manufacturers to demonstrate that their aircraft can operate safely in an SLD environment for a period of time to facilitate a safe exit from the condition. It is anticipated that aircraft manufacturers will require a capability to demonstrate compliance with this rule via experimental means (icing tunnels or tankers) and by analytical means (ice prediction codes). Since existing icing research facilities and analytical codes were not developed to account for SLD conditions, NASA and its partners conceived a strategy or Roadmap for developing experimental and analytical SLD simulation tools. Following review and refinement by the airworthiness authorities and other international research partners, this technical strategy has been crystallized into a project plan to guide the SLID Engineering Tool Development effort. This paper will provide a brief overview of the latest version of the project plan and technical rationale, and provide a status of selected SLD Engineering Tool Development research tasks which are currently underway.

14. SUBJECT TERMS

Aircraft icing; Aircraft safety

\begin{tabular}{|c|c|c|c|}
\hline $\begin{array}{c}\text { 17. SECURITY CLASSIFICATION } \\
\text { OF REPORT } \\
\text { Unclassified }\end{array}$ & $\begin{array}{c}\text { 18. SECURITY CLASSIFICATION } \\
\text { OF THIS PAGE } \\
\text { Unclassified }\end{array}$ & $\begin{array}{c}\text { 19. SECURITY CLASSIFICATION } \\
\text { OF ABSTRACT } \\
\text { Unclassified }\end{array}$ \\
\hline
\end{tabular}

NSN 7540-01-280-5500 

